\title{
De autónomos y atarantados
}

doi: http://dx.doi.org/10.32870/

espiral.v23i65.4461.g4203

Martín Gabriel Reyes Pérez

Tarántula, institución y hacer pensante por la autonomía. Castoriadis en la trama latinoamericana entre la academia y la política es un excelente libro que acota con total claridad, desde el título mismo, el territorio en el que se inscriben los capítulos que lo componen. Se trata de un texto que promueve una manera novedosa de incursionar en la obra escrita e institucional del filósofo griego Cornelius Castoriadis, y que es descrita con precisión en una de las frases del título: es un "hacer pensante por la autonomía". En acuerdo con esto, constituye una de las concreciones de un amplio diálogo que se inició en el año 2009 con el propósito de fundar una "obra institucional" por la autonomía entre los académicos y militantes de izquierda mexicanos.

Precisamente, el concepto de "obra institucional" articula de manera indisociable el hacer y el pensar, que a su vez dan vida y nutren a la autonomía, entendida esta como acción deliberada y reflexiva mediante la cual un sujeto se da a sí mismo la ley que rige su existencia y una sociedad se reconoce como la fuente única de creación de las instituciones que la definen. Así, los textos que se "tejen" en este libro pueden ser considerados castoridianos,

Rafael Miranda Redondo, Dolores Camacho Velázquez y Jorge Alonso (coords.) (20l4). Tarántula, institución y hacer pensante por la autonomía. Castoriadis en la trama latinoamericana entre la academia y la política. México: Centro de Investigaciones y Estudios Superiores en Antropología Social. 
no tanto por el empleo de tales o cuales de las categorías introducidas por este filósofo, sino porque constituyen en sí mismos modalidades del hacer pensante que caracterizó la obra escrita e institucional de Castoriadis. La "obra institucional" alude tanto a los escritos como a los dispositivos institucionales que generó Castoriadis, a su pensamiento y a su arraigo institucional, al hacer pensante y a la acción en el mundo, al cambio social y a su implicación afectiva, corporal, subjetiva en la transformación revolucionaria. Además, el concepto de "obra institucional" resitúa el andamiaje y las finalidades de la investigación social, imprimiéndole una intencionalidad revolucionaria al trabajo del conocimiento, pues si bien el dispositivo de investigación de suyo perturba la realidad al intervenir en ella, desde la óptica de Castoriadis esa perturbación se direcciona en el sentido de la transformación revolucionaria, concretada en la creación de la sociedad autónoma en proyecto.

El "hacer pensante" es otro de los nombres de la dimensión instituyente del imaginario radical, engarzado permanentemente en un enfrentamiento agonístico con lo instituido, aspecto que también está aludido en el título. Por ello, los autores de los distintos capítulos no se limitan a ofrecernos descripciones o explicaciones de las prácticas y movimientos sociales que bregan cotidianamente por la autonomía, sino que diagnostican y elucidan el flujo del "magma imaginario" que adquiere formas siempre provisorias e inestables, como instituciones y significaciones sociales. La dialógica que se instaura entre el imaginario creador e instituyente y las formas institucionales es considerada desde el ángulo de la crítica, la resistencia y la creación contrainstitucional en los ámbitos en los que los autores se implican, sea en el ágora o en la academia. Lo anterior permite entender que este libro no sea el muestrario de la erudición de los autores, sino un momento en una trayectoria reflexiva, así como el índice del firme compromiso por una reflexión comprometida 
que se despliega en varios territorios y momentos tejidos, en cierto modo, al paso de una tarántula.

Uno de esos territorios ha sido el conjunto de seminarios y talleres de discusión que dieron cuerpo a la Cátedra Internacional Cornelius Castoriadis (CICC), y en los que se promovió un diálogo sobre la obra institucional por la autonomía, diálogo que, ya lo dijimos, era también un hacer, una acción sobre el mundo, en el que se implicaron tanto activistas como académicos de México, América Latina, Estados Unidos y Europa. Por cierto, el diagrama de flujo de la CICC se encuentra en la página 79 de este libro y en su versión primera, con marcadores y papel, se asemejaba a una tarántula, o al menos así le pareció a Susan Street cuando desplegó su imaginación radical en la ceremonia de clausura del "Primer Encuentro Internacional. La creación humana", que tuvo lugar en la Casa de la Primera Imprenta de América, en México, D. F., en octubre de 2011, siendo otro de los momentos de esta "obra institucional" y también otro de los pivotes del diálogo que vivifica a este libro, pues la primera versión de la mayoría de los capítulos que lo constituyen se presentaron en esa ocasión y lugar. Como bien precisa Rafael Miranda, en el excelente prólogo de este libro polifónico, la alusión a la "tarántula" en esa ceremonia de clausura no sólo se motivaba en la pregnancia visual, sino que era una manera afortunada de situar la complejidad que singulariza el pensamiento castoridiano, así como la trama en red que se había tejido minuciosamente tanto en la Cátedra como en ese encuentro. En esto reside, precisamente, la singularidad de la CICC y de este libro: inauguran una nueva manera de acercase a la obra escrita e institucional de Castoriadis, en la que no sólo se trata de "hablar y escribir sobre la autonomía, sino también [de] ponerla en práctica" (p. 309); se trata de pensar la autonomía y de hacerla pensando. 
Han sido los coordinadores del libro quienes han hilado estos espacios dialógicos y reflexivos, además de formar parte, al igual que el conjunto de autores que aquí se dan cita, de esa trama latinoamericana entre la academia y la política mencionada en el título. Ninguno de ellos es un "consumidor de ideas", ni escriben para lectores que así podrían ser caracterizados: son académicos y militantes implicados en el ejercicio creador de espacios multiformes de autonomía. Más aún, puedo decir, basándome en lo que se trasluce en los capítulos que escribieron y en lo que deduzco de aquellos a quienes tengo el honor de conocer en lo personal, se atienen estrictamente a los corolarios que derivan de esta frase de Rocío Salcido: "[...] la posibilidad de apropiarse la herencia de este filósofo griego plantea una mediación: que el sujeto se reconozca como expresión de formas emergentes de socialidad y participe en las prefiguraciones de formas nuevas de institucionalidad" (p. 190). Y es que el ejercicio de apropiación de esta herencia no puede reducirse a un ejercicio de erudición o exégesis escolástica, sino que exige una implicación crítica y reflexiva, así como un compromiso de cuerpo entero en una praxis inscrita en el sentido de la obra institucional por la autonomía. No podría ser de otra manera, por lo demás, tratándose de un libro escrito en la estela del pensamiento de Castoriadis, filósofo, ciudadano y psicoanalista quien, en sus argumentos, pero sobre todo en su vida cotidiana, promovió y dio cuerpo al lazo inextricable entre la psique y la sociedad, entre los afectos y las representaciones, entre el pensar y el hacer.

Si bien los distintos autores del libro hacen uso crítico de diversas categorías de Castoriadis, el "encargo" inicial que dio lugar a esta red compleja deja su sello en sus argumentos, de manera que el concepto de autonomía termina siendo el hilo conductor que subtiende la mayoría de los textos. Ateniéndose de manera coherente a la radicalidad reflexiva del pensamiento castoridiano, el propósito inicial 
de dar a conocer la obra institucional y escrita del filósofo griego tomó forma en la creación de un dispositivo institucional -es decir, una obra institucional en sí misma-, tejido como una trama compleja de hilos y lienzos. Es por eso que no encontraremos en los distintos capítulos una presentación sistemática de la obra de Castoriadis, pero sí un tejido flexible hecho de entrecruzamientos con otros autores, la exploración de algunos conceptos, así como una urdimbre de acuerdos y desacuerdos con este singular filósofo-ciudadano.

Esta red sutil de significaciones está dibujada con precisión en el prólogo, donde Rafael Miranda hace un retrato conciso de cada capítulo, subraya con minucia las conexiones entre las distintas argumentaciones, señala el diálogo que los autores entablan con el filósofo griego y pondera las tensiones a las que es sometida la obra institucional y escrita de Castoriadis cuando lo que se ambiciona es

[...] precipitar las nociones principales de ese autor a categorías intermedias que nos permitan intervenir, por momentos, en el sentido de una obra institucional por la autonomía, en y a contracorriente, del magma de significaciones imaginarias sociales en el que estamos inmersos (p. 16).

Con todo y esto, en la estructura en red de este libro destacan los hilos vertebrales de las tres "profesiones imposibles" delimitadas por Sigmund Freud, y que Castoriadis considera como las prácticas merced de las cuales los sujetos y las sociedades se transforman en el sentido de la autonomía radical, prácticas que a su vez se corresponden con distintos territorios de lo público-privado: "la educación-formación y el psicoanálisis que se ejercen en el espacio de lo privado público; el ágora y la política, que se ejercen en el espacio propiamente político; y la eclesia” (p. 18).

Es necesario destacar que no podrá encontrarse en Tarántula... el santo y seña de un "-ismo" que recurra al 
apelativo de Castoriadis, pues los autores no conforman una grupalidad que trace la frontera entre el adentro y el afuera, entre los que son castoridianos y los que no lo son, a la manera de esos psicoanalistas que se enfrentan en luchas merovingias con el propósito de determinar cuál es la interpretación fiel de la palabra de Lacan, para luego instaurar con petulancia las jerarquías inamovibles entre los seguidores, los discípulos y los herejes. Tanto los autores como el libro en su conjunto se encuentran a distancia de eso que Miranda llama "falacia del sujeto" y que articula en el siguiente aforismo: "yo estoy/soy el bien, tú no eres yo, por tanto tú no estás/eres el bien, tus dioses no son verdaderos" (p. 74). De hecho, nada sería más contrario al hacer pensante de Castoriadis que la pretensión de convertirlo en una obra cerrada y sistemática, o en un corpus que sostiene y brinda consistencia a la identidad de los adeptos, pues el permanente ejercicio de reflexividad e imaginación creadora en el cual consiste y que promueve, delega, en el campo social, la tarea de probar los ejercicios de elucidación que se direccionan hacia la autonomía en proyecto, por lo que no está constituido en la fidelidad y el apego a principios doctrinarios.

Lo anterior nos permite calibrar la importancia de la "obra institucional" (pensar-hacer) para las ciencias sociales pues, tal y como lo afirma en el capítulo respectivo Cristophe Premat, la sociedad autónoma en proyecto tiene como corolario -mejor aún, como condición ineludible- la articulación o combinación de disciplinas que tradicionalmente han sido separadas en compartimentos estancos: la filosofía, las ciencias sociales, el psicoanálisis; esfuerzo de articulación que tiene en Castoriadis al más logrado de sus representantes.

Esto vale para los métodos de enseñanza y de construcción del conocimiento en la medida en que la autonomía, como significación imaginaria social, conlleva el cuestiona- 
miento permanente de las modalidades esclerotizadas de lo instituido. En mayor o menor medida, y con menor o mayor fortuna, los autores de este libro participan de este ingente esfuerzo por la articulación inter- y transdisciplinaria. De hecho, Rafael Miranda me brindó una muestra más de su conocimiento meticuloso del psicoanálisis al contestarme la pregunta que le formulé, con ocasión de la presentación de este libro en las instalaciones del CIESAS-Occidente, en octubre del 2014, acerca de la genealogía y los alcances de la metáfora de la tarántula y el tarantismo, con una frase en extremo divertida: "lo que yo hice fue una novela familiar", aludiendo con ello al conocido texto de Freud que lleva como título La novela familiar del neurótico (texto publicado en 1909, en el que el creador del psicoanálisis da cuenta de las vías y estadios mediante los cuales el niño se enajena de los padres). A contrapelo de este lúcido (y lúdico) comentario, y de las precisiones de Rafael Miranda en el prólogo, considero que, al utilizar la metáfora e imagen de la "tarántula", los coordinadores del libro problematizan el abordaje dicotómico de la dialéctica que media entre autonomía y heteronomía y, como corolario, replantean la crispación del supuesto enfrentamiento entre Cornelius Castoriadis y Jacques Lacan en torno a los alcances del psicoanálisis.

Aclaro que en modo alguno pretendo llevar a cabo una hermenéutica de las intenciones de los coordinadores, o alguna modalidad de "lectura sintomal", tal y como fue promovida por Althusser; parto simplemente de la materialidad de lo dicho y lo escrito para subrayar que el despliegue del imaginario creador no coincide necesariamente con la intencionalidad consciente. Por otro lado -y ateniéndome a los corolarios del bello cuento de Edgar Allan Poe, "La carta robada", al que Lacan recurre, entre otras cosas, para cuestionar la anticuada noción de "psicología de las profundidades"-, sostengo que los coordinadores de este libro mantienen "escondidas", o en estado "latente", las 
implicaciones significativas de la "tarántula" precisamente al relevar su significante e imagen.

Como es sabido, mientras Castoriadis plantea que el psicoanálisis abona decididamente a la andadura de la autonomía radical, la postura de Lacan podría condensarse en la conocida frase que se encuentra en Escritos 1: "La heteronomía radical que el descubrimiento de Freud pone al descubierto como hiancia en el hombre no puede ya recubrirse sin hacer de todo lo que se use para ese fin una deshonestidad de fondo" (Lacan, 1993, p. 504).

Si bien sería perfectamente demostrable que el planteamiento de Lacan, en apariencia extremo, tiene su genealogía en la crítica ácida a los postulados de corte ideológico de la llamada "psicología del yo", según los cuales sería posible delimitar la existencia de un segmento del "yo" autónomo y libre de conflictos e, incluso, que esta crítica coincide en lo esencial con la que se implica en la "falacia del sujeto", a la que ya me referí, dejaré esto de lado para, en cambio, subrayar las implicaciones, en lo que respecta a la dialéctica autonomía/heteronomía, de la investigación histórica y sociocultural llevada a cabo por Ernesto de Martino en 1959 y que presentó dos años después en su libro La terra del rimorso (la versión en español de La tierra del remordimiento apareció en 1994, en Barcelona, gracias a Ediciones Bellaterra), en el cual aborda el tarantismo en la región de Apulia, particularmente en el Salento (el "tacón" de la "bota" itálica). Antes debo subrayar que el entusiasmo de los coordinadores de Tarántula... contrasta con la gélida referencia de Nietzsche al tarantismo en Así hablaba Zaratustra, en el que atribuye a estos singulares bichos el poder de inocular en los hombres el espíritu de venganza, veneno que provoca las apelaciones convulsas a una justicia que se alimenta, sin embargo, del mero resentimiento, esa moral de esclavos que singulariza al cristianismo: Zaratustra afirma con 
vehemencia que jamás será picado por la tarántula, pues el baile dionisiaco nada tiene que ver con la tarantela.

Situándonos al ras del diccionario, habría que partir del hecho de que la condición de "atarantado o atarantada" - propia de los que han sido picados por la tarántula- es contraria a la que caracteriza al sujeto reflexivo y deliberante, si consideramos que algunas de sus significaciones son "inquieto y bullicioso, que no para ni sosiega", "aturdido o espantado", o bien "loco, de poco juicio" (el diccionario de sinónimos nos ofrece: atropellado, aturullado, aturdido, distraído, azorado, confuso, desconcertado). Esto se confirma si enfocamos el cuadro clínico del tarantismo apuliano que, en la mayoría de los casos analizados por De Martino (1994), "siempre imitaban, más o menos burdamente, el síndrome tóxico real” (p. 53) llamado latrodectismo, el cual es provocado por la picadura de arañas del género latrodectus, al que pertenece la "viuda negra":

La caída al suelo, la sensación de postración, la angustia, el estado de agitación psicomotora con obnubilación sensorial, la dificultad para mantenerse en pie, el dolor de estómago, las nauseas y el vómito, las parestesias, los dolores musculares y la exaltación del apetito venéreo (De Martino, 1994, p. 52).

Si bien el hilo vertebral de la investigación liderada por De Martino es la historia de las religiones, el equipo interdisciplinario a su cargo contaba con especialistas en los campos de la psiquiatría, la psicología, la etnomusicología y la antropología cultural, de manera que pudo establecer "la autonomía simbólica del tarantismo" (De Martino, 1994, p. 53), entre otras cosas porque pocos atarantados habían padecido realmente latrodectismo (luego entonces no se trataba de casos reales de envenenamiento o psicosis). Puesto que los atarantados atribuían la causación de sus síntomas, así como las crisis anuales que los aquejaban, a la 
mordedura de la tarántula, la que es prácticamente inocua para los seres humanos, esta mordedura constituye una metáfora indiscutible, no sólo de la "alteridad radical", sino de la heteronomía que postra y convulsiona al atarantado. La faceta religiosa del tarantismo -que a mi juicio es otra concreción de la heteronomía-se manifestaba con claridad en la procesión, a fines del mes de junio, a la iglesia de san Pablo en la ciudad de Galatina, apóstol que brindaba su auxilio para exorcizar la personalidad de la tarántula, inoculada también con su mordedura.

El ritual curativo del tarantismo consistía en un exorcismo basado en los colores, en la danza y en la música -de cuyas notas y compases surgió la danza de la tarantela-, mientras que la eficacia simbólica de la cura le permitía al atarantado procesar conflictos existenciales reprimidos, al menos hasta el momento en que era "mordido" de nuevo por la tarántula. Siendo una "práctica que trama sentido representación, intención y afecto- y crea sentido nuevo" (p. 13), Rafael Miranda considera que la lógica del tarantismo es convergente con el proceso de autoalteración social en el ámbito del inconsciente, entendido como alteridad, es decir, como "el otro que nos habita". Esta es una de las razones que justifica equiparar el ritual del tarantismo con las tres profesiones imposibles que aspiran a crear autonomía, si bien la pregunta que es pertinente plantear aquí es: ¿qué resultaba del ritual curativo del tarantismo?, o bien: ¿en qué se transformaba el atarantado al ser exorcizado? Los datos que recogió De Martino en su investigación permiten, a mi juicio, arribar a la siguiente respuesta: este exorcismo no culminaba en mayores cotas de reflexividad y autonomía, sino en un apaciguamiento provisorio del remordimiento, hasta que una nueva mordedura exigía el recurso a una nueva curación. Y es que los conflictos, traumas y frustraciones que estaban en la base de los fenómenos psicosomáticos propios de la crisis del atarantamiento sólo accedían a la 
conciencia con la mediación del símbolo de la tarántula, y gracias al ritual se modelaban culturalmente, se enlazaban a otros símbolos, se transmutaban en música, danza y colores, pero, en lo esencial, permanecían opacos y en su condición de "alteridad radical".

Dicho en otros términos, la represión, en el sentido psicoanalítico, no se levantaba, razón por la cual el atarantado no recordaba, rememoraba o reflexionaba sobre los conflictos que lo aquejaban. Vamos, ni siquiera consideraba que lo que subyacía a su atarantamiento eran conflictos y frustraciones, pues para él todo lo que le ocurría había sido provocado por el remordimiento de la tarántula.

Esto último me sugiere que, al privilegiar la imagen y el significante de la tarántula (y del tarantismo), los coordinadores de este magnífico libro abren otras avenidas para replantear los alcances de la autonomía radical. Una de esas avenidas me lleva a pensar que el advenimiento de un sujeto reflexivo y deliberante tendría como condición el establecimiento de una pausa entre una mordedura y otra, un desacoplamiento parcial y provisorio de la alteridad radical (por tanto, de la heteronomía), lo que abriría las esclusas de la imaginación creadora para así desbordar lúcidamente el marco de lo instituido. De ser así, la autonomía radical podría formularse de esta manera: no ser tan tonto como para atarantarse tanto, merced de lo cual podríamos decir, tomando distancia del talante de Nietzsche, que la danza de la autonomía no es otra que la tarantela.

De Martino, E. (1994). La tierra del remordimiento. Barcelona: Bibliografía Ediciones Bellaterra.

Lacan, J. (1993). Escritos I. México: Siglo XXI. 